\title{
Systems Thinking and Practice for Telecommuting Issues
}

\author{
Subrahmanyam Kodukula \\ Professor \\ Department of CSE, KL University \\ Vaddeswaram, Guntur Dt., India
}

\begin{abstract}
Systems thinking approach for solving business, social and engineering problems always view individuals and organizations within the context of their environments. Soft Systems Methodology (SSM) developed by Peter Checkland takes this approach in solving complex ill-defined problems. This research paper applies Systems Thinking and practice to telecommuting issues identified, and attempts to discover the possible strategies / practicable approaches to encourage telecommuting in Small and Medium Enterprises (SME). The reasons for the lack of telecommuting in SMEs of Malaysian ICT sector were identified from our past research and this research starts with a hypothesis that the telecommuting problems can be addressed using Systems Thinking approach.
\end{abstract}

\section{General Terms}

Small and Medium Enterprises, ICT, Hypothesis.

\section{Keywords}

Systems Thinking, Telecommuting, Soft Systems Methodology, Systems Approach, Change Control Board.

\section{INTRODUCTION}

The telecommuting also known as remote working is a distributed work arrangement that can be defined as the work or activity conducted by groups or teams of people separated from each other in time and space, with advance communication technologies being used to co-ordinate the work process taking place [1].

The two general types of telecommuting are telecommuting from home and telecommuting through a centre setup by the office. The most common form of telecommuting that most people prefer is home-based in which the employees works from their respective houses. The centre based telecommuting is a place where employees can go and link to their office and do their work at the centre rather than commuting to the office. The success or failure of remote working depends on a variety of conditions, which varies in different environments. The usual requirement in today's remote working setting is technological equipment such as a networked computer, with a fast internet connection and naturally, the hardware and software to support this [2]. There also exists the other aspect of an effective remote working environment, that being the worker him/herself. The question of whether the employee is suitable for remote working lies whether the employer trusts the employee as well as the characteristic of the particular individual [3].

Our past research [4], which used deductive research approach, has concluded that productivity levels of telecommuters are higher than non-telecommuters and the stress levels of telecommuters are lower than non-telecommuters in Malaysian ICT sector. However, it also identified some reasons for the lack of telecommuting, especially in SMEs of Malaysian ICT sector. They include Nature of work organization, Trust, Supervision issues, Communication difficulties, Security and Privacy, High cost of setup, Lack of skills and Career path anxiety.

This research paper took the above identified reasons as basis for lack of telecommuting programs in SME's of Malaysian ICT sector and attempted to address these issues by applying Systems Thinking via Checkland's Soft System Methodology and concludes that the Malaysian SMEs can deploy TC successfully provided they perform the necessary feasibility study, come up with a clear business plan, create a CCB with in the organization and prepare the people in the organization with adequate trainings..

\section{RESEARCH STRATEGY AND DESIGN}

The primary research approach was action research. It aims to contribute both to the practical concerns of people in an immediate problematic situation and to the goals of social science by joint collaboration within a mutually acceptable ethical framework [5]. Its nature involves: simultaneously bringing about change in the project situation (the action) while learning from the process of deriving the change (the research) [6] [11]. The action research cycle of theory and practice by Checkland and Scholes (1990) as cited by Rose (2002) shown in Figure 1 was used as a basis by author.

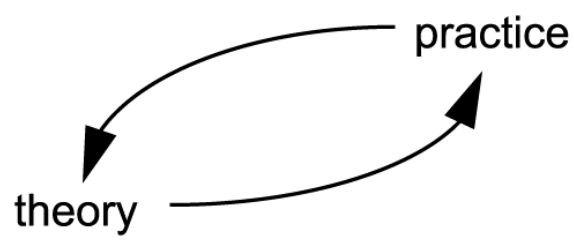

Figure 1. Action research cycle 
Research was designed based on the frame work suggested by Checkland (1991) shown in Figure 2.

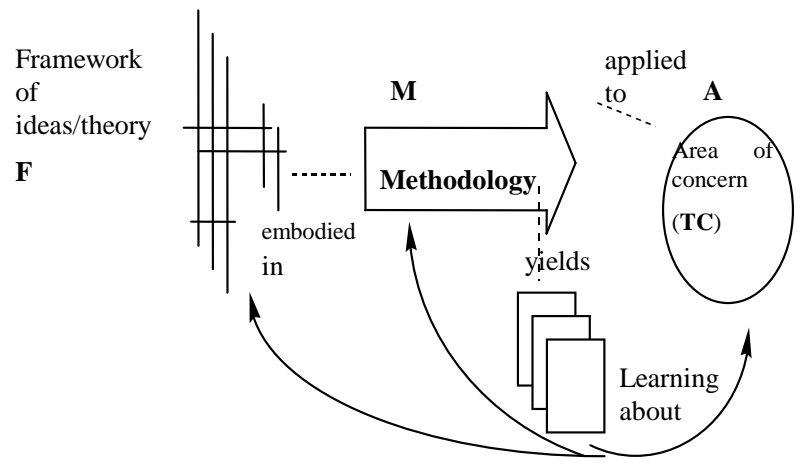

Figure 2. FMA Framework for Action Research (Checkland, 1991)

\section{SOFT SYSTEMS METHODOLOGY (SSM)}

SSM is a technique developed by Peter Checkland and colleagues at University of Lancaster that can be used for applying Systems Thinking to non-systemic situations [10]. They had the knowledge of systems engineering and wanted to use this knowledge to solve practical systems and so they came up with four key characteristics that shaped SSM:

- $\quad$ Situations are mostly people-based, once looked at from a higher point of view.

- There are many ways to perceive the stated objective of systems.

- To move away from a problem that seemed 'obvious' to one that is considered a situation.

- That models of purposeful activity can provide an entry to work on information systems.

SSM is based upon systems theory. Systems theory attempts to study the whole picture; the relation of component parts to each other, and to the wider picture [5]. SSM has developed considerably since Checkland's original contribution and there is now an extensive literature devoted to various approaches to SSM as well as applications. The methodology, however, has not gained a strong foothold in mainstream management thinking or practice, nor is it widely known in HRM [6]. It is necessary, therefore, to outline the basic approach and its underlying philosophy, before looking at how it may be used to support the purpose described here.

SSM provides a framework for dealing with complex ill-defined problem situations. With roots in the hermeneutic/phenomenology/interpretive tradition, systems concepts are used as an epistemological device to facilitate learning about problem situations with a view to taking action which is acceptable to the key stakeholders involved. Essentially SSM is a specialized form of action research where the aim is to improve practices and understanding of situations through participants' self-reflective enquiry [7].

\subsection{Stages in SSM:}

The original SSM model developed by Checkland has seven stages as shown in Figure 3. The seven stages, numbered in the illustration, are distilled from an iterative process, so, in practice, the process can begin anywhere. Usually there is a good deal of movement forwards and backwards between the various stages [7]. Stages 1 and 2 in a traditional SSM study are "finding out" stages, the outcome of which is captured in a "rich picture" of the problem situation. A rich picture is a representation of the problem situation, presented usually in the form of a drawing, which makes explicit a range of diverse viewpoints concerning issues, conflicts and difficulties. It draws attention to cultural and political aspects of the problem situation and attempts to provide a complete picture of what is going on rather than reducing problems to their component parts. These include various tasks which have to be completed, like responding to briefs and writing reports. It highlights a number of issues including the problem of excessive work overload, difficulties in dealing with sometimes conflicting responsibilities, and major concerns which relate to the various relationships between the project manager and relevant others including clients, research directors, other project managers, field and support staff.

Identifiable themes from the rich picture are restated as notional systems in stage 3 . Here the mnemonic CATWOE is used as a guide to produce root definitions (RDs) of these systems. RDs make explicit the complete nature of the system in question by defining customers $(\mathrm{C})$, actors $(\mathrm{A})$, and the transformation process $(\mathrm{T})$, owners $(\mathrm{O})$, environmental constraints (E) and, importantly, the subjective worldview, or Weltanschauung (W), which gives the system meaning.

In stage 4 the conceptual models (the activity models) of these potential systems will be drawn. The activity model is a description of the activities which need to be done for the system to perform the transformation process of the root definition.

In stage 5 the comparison of the real and conceptual worlds will be carried out, which should lead to suggestions for improvement and action on those suggestions in stages $6 \& 7$ respectively. This implies that SSM practitioners follow a step-by-step logical progression in their investigations, however at times the stages are taken out of order or even omitted if the situation dictates [8]. 


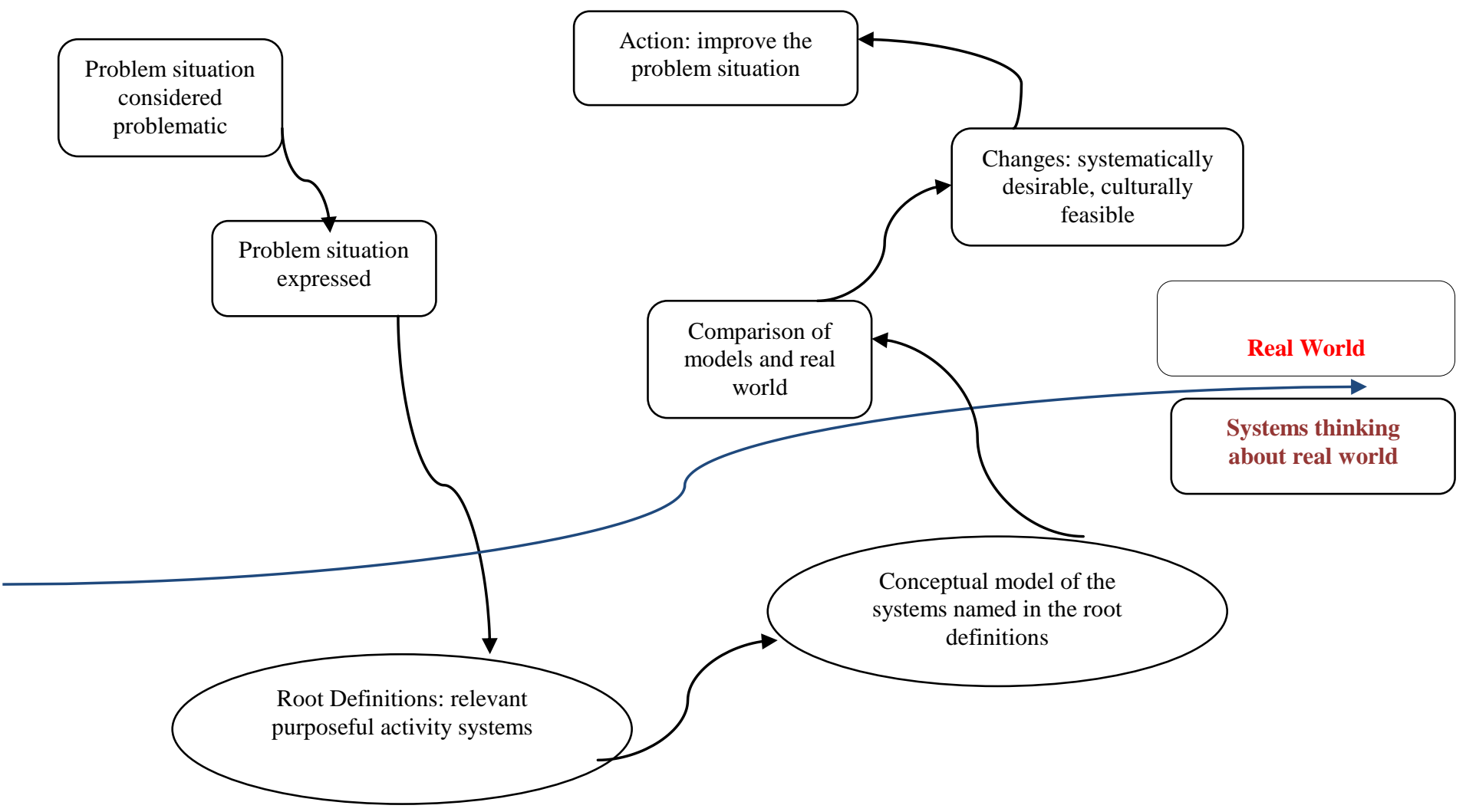

Figure 3. Seven stages of SSM by Checkland

\section{SSM APPROACH TO TC ISSUES}

\subsection{Stage1: Problem identification}

Through our past research [4] in Malaysian SMEs of ICT sector, the problems related to TC were identified as follows:

- "Nature of work" of Organization - means that the work performed in the organizations has no scope for telework.

- $\quad$ Trust - expectation and trust between employees and employers haven't reached required level in Malaysia for demeanor telecommuting processes.

- Difficult to Supervise - employers feel that employees who are not attached to a particular physical working place and time are difficult to be supervised. This is also a trust issue.

- Communication difficulties - the communication problems due to technical issues like unstable connections, low band width, etc.. were expressed by both employees and employers.

- Security and privacy - all technical issues related to security and privacy are also hindrance to TC as per both employees and employers.

- High cost of set up - employers feel that the procedures can be complicated and very costly - it means, cost and

- Complication still do not match with the affirmative outcome from TC.

- Lack of skills - skills required to be a professional telecommuter are limited.

- Career path anxiety- employees have fear of management not noticing when they telework and consider it as an obstacle to move higher in career. 


\subsection{Stage 2: Problem Situation Expressed, the "Rich Picture}

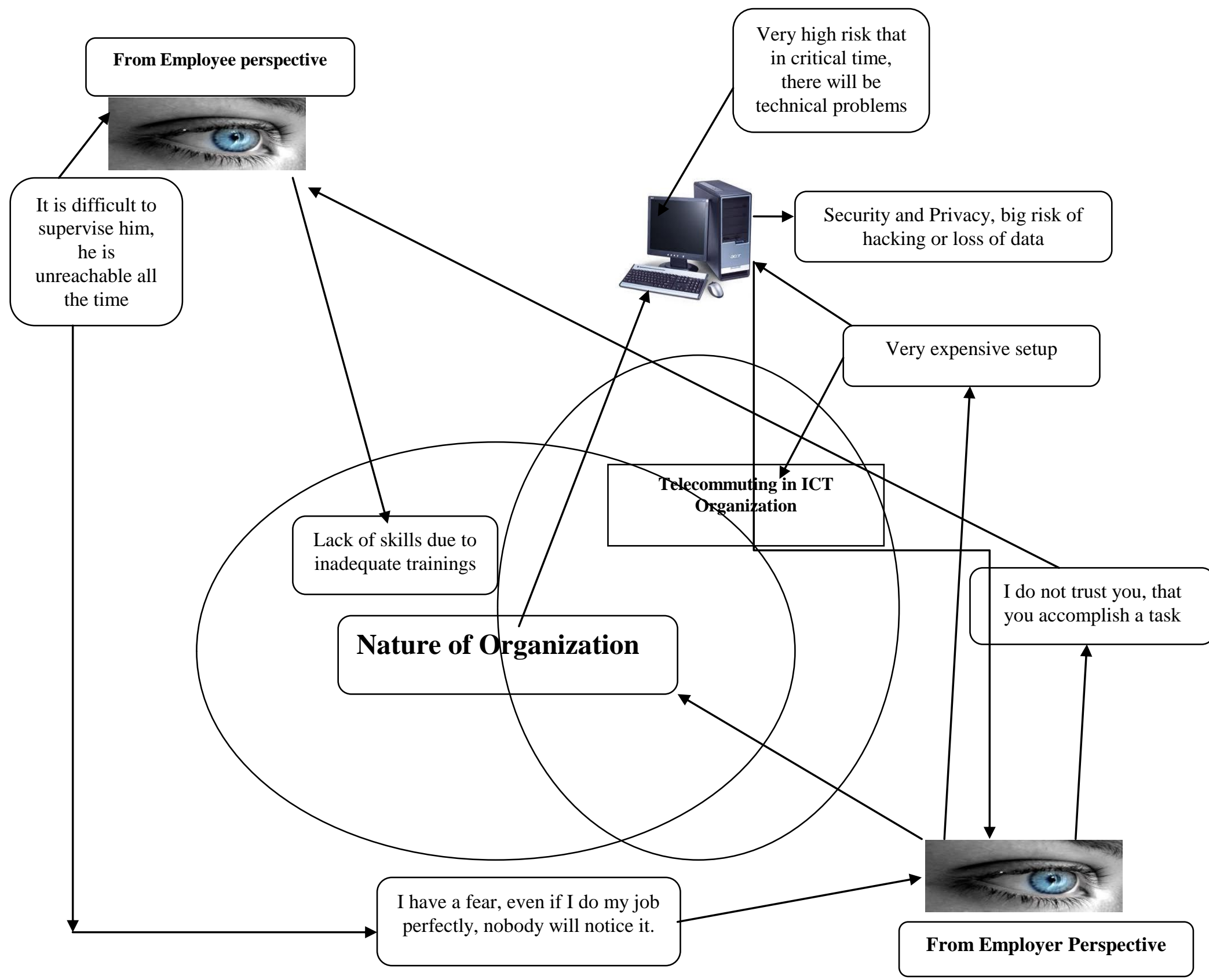

Figure 4 . "Rich Picture" - Telecommuting Problems in Malaysian ICT sector

\subsection{Stage 3: Root Definitions of relevant systems}

\subsubsection{CATWOE Analysis for TC}

The Customers: Employers and employees of SMEs of Malaysian ICT sector
The Actors: The researchers who try to bring an innovation, the Implementers those who will be responsible for conveying and watching the process.

The Transformation: To transfer non-telecommuting SMEs to telecommuting SMEs.

The Weltanschauung: Creating highly conducive/productive remote working environment in Malaysian ICT sector. 
The Owners: Top- Management and Steering Committee who are willing to implement telecommuting and the researchers who develop the method.

Environment: Political, Cultural, Technical boundaries and available resources in this area.

By understanding the relevant issues present and constructing a CATWOE analysis based on the system boundaries, the authors finalised the root definition (RD), which encapsulated the very essence of what the systems purpose is in accordance with the CATWOE analysis.

\subsubsection{Root Definition}

'To encourage telecommuting in Small and Medium Enterprises of Malaysian ICT sector for creating a harmonious conducive working environment for employers and employees of these organizations and reduce stress among employees with an ultimate aim of increasing organization's productivity.'

\subsection{Stage 4: Conceptual Model}

In this stage the study attempts to form model of activities for root definition, keeping in mind 3Es- Efficacy, Efficiency and Effectiveness.
Feasibility and planning - A good analysis/feasibility study of the necessity of TC related to organization and appropriate business planning to implement it if the necessity of TC has been confirmed through feasibility study, showing how to deploy and implement the telework in reality within the organization is required.

The feasibility study should cover technical, operational, social and economical aspects.

Change Control - There should be a Change Control Board (CCB) focusing on identifying, evaluating, and managing possible changes throughout after deploying TC in the organization.

Social Improvement - If misunderstanding and mistrust between actors occurs during or before deployment, they must terminate all disputes and achieve a harmonious working environment.

Training - it must be provided to the staff by top-management before any implementation and also include re-training when and where necessary.

Rewards - Employee's effort towards successful TC must be appreciated and rewarded.

The graphical form of the conceptual model represented in Figure 5 .

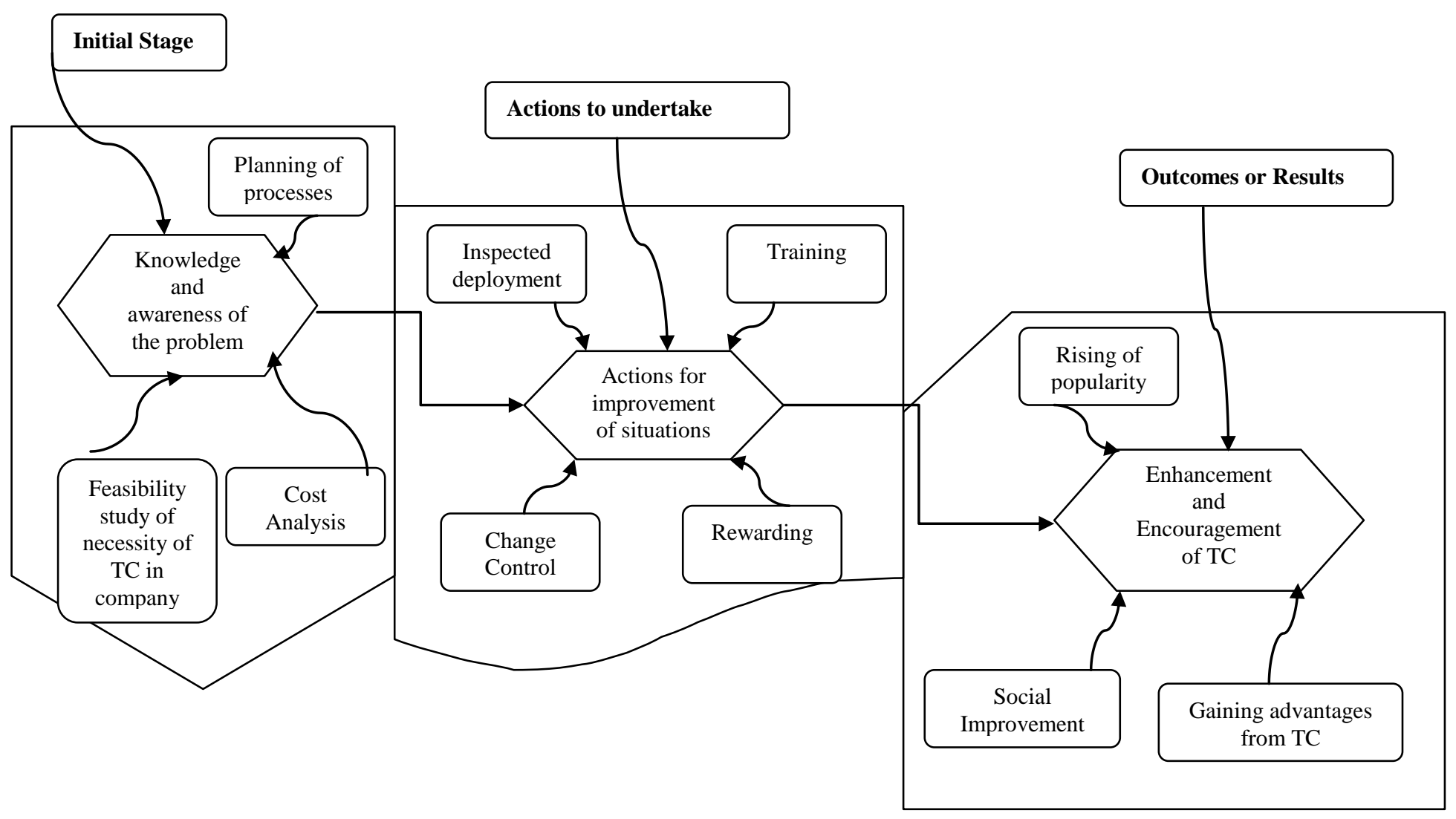

Figure 5 . Conceptual model for TC 


\subsection{Stage 5: Comparison of conceptual model to Reality}

The below matrix analysis gives the comparison between "The Real world" and "Conceptual Model"

Table 1: Real world and Conceptual world comparison

\begin{tabular}{|c|c|c|c|}
\hline Model Real & $\begin{array}{l}\text { Does it exists in the real world and how does it } \\
\text { behave? }\end{array}$ & $\begin{array}{l}\text { How is its } \\
\text { performance identified } \\
\text { and measured? }\end{array}$ & Is this process any good? \\
\hline $\begin{array}{l}\text { Feasibility } \\
\text { study and planning }\end{array}$ & $\begin{array}{l}\text { It exists in all MNCs; however SMEs are } \\
\text { neglecting the feasibility study and proper } \\
\text { business plan before deploying TC. }\end{array}$ & $\begin{array}{l}\text { It can be used as a } \\
\text { bench mark by all } \\
\text { organizations for } \\
\text { monitoring } \\
\text { progress of any } \\
\text { process within the } \\
\text { organization. }\end{array}$ & $\begin{array}{l}\text { Yes, by this process } \\
\text { companies can avoid } \\
\text { unnecessary } \\
\text { deployment and can be } \\
\text { confident if at all they go } \\
\text { for TC. }\end{array}$ \\
\hline Change Control & $\begin{array}{l}\text { In reality there is lack of this kind of body in } \\
\text { many SMEs to monitor the changes due to the } \\
\text { deployment of TC. }\end{array}$ & $\begin{array}{l}\text { Through Quality } \\
\text { control procedures and } \\
\text { management reviews }\end{array}$ & $\begin{array}{l}\text { Yes, it gives better quality } \\
\text { in relation to Technology, } \\
\text { Human resources and } \\
\text { Economical aspects }\end{array}$ \\
\hline $\begin{array}{l}\text { Social } \\
\text { Improvement }\end{array}$ & $\begin{array}{l}\text { To some extent this is not a big problem in } \\
\text { Malaysia, which is a multi racial and multi } \\
\text { cultural country. Only few employers expressed } \\
\text { the trust as an issue. This can be addressed by } \\
\text { conducting appropriate team building activities, } \\
\text { etc... }\end{array}$ & $\begin{array}{l}\text { By various team } \\
\text { building activities and } \\
\text { appraisal systems }\end{array}$ & $\begin{array}{l}\text { Though it plays a major } \\
\text { role in TC deployment, it is } \\
\text { not a big issue in Malaysian } \\
\text { context. }\end{array}$ \\
\hline Trainings & $\begin{array}{l}\text { The trainings were not much focused and re- } \\
\text { trainings were provided to a little extent only. } \\
\text { This actually can address even the trust issues. }\end{array}$ & HR training plans & 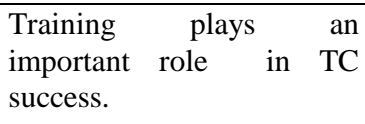 \\
\hline Rewards & $\begin{array}{l}\text { It exists, but is inadequate to an extent to } \\
\text { motivate and employees have anxiety of career } \\
\text { path }\end{array}$ & $\begin{array}{l}\text { Through } \\
\text { appraisals }\end{array}$ & $\begin{array}{l}\text { Doesn't play a very big } \\
\text { role, however should have } \\
\text { a kind of appreciation. }\end{array}$ \\
\hline
\end{tabular}

\subsection{Stage 6 \& 7: Desirable Changes and Actions needed}

From the above comparison of real world and conceptual world in relation to $\mathrm{TC}$, it is evident that the organizations need to conduct an appropriate feasibility study and prepare business plan before deploying TC and also to frame a CCB to monitor and control changes . CCB should meet regularly to monitor and control desirable changes.

The CCB [9] should actually

- Influence the factors that create changes to ensure they are beneficial

- Determine that a change has occurred

- Manage actual changes when and as they occur

After successful feasibility study, the organizations must create awareness among the participants involved through various channels like internal media, mails, seminars/conferences, etc..to realize the need and appreciate TC within the organization. This would really clear many problems/concerns raised.
The other area of concern is Training. Organizations need to incorporate teleworking skills into existing IT and management training programmes, which also should establish a monitoring and accountability system for telecommuting that can help eventually in appraisal system aswell to give the necessary rewards. This will in due course encourage all staff to gain necessary knowledge in TC and appreciate the advantages of it.

\section{CONCLUSIONS}

The telecommuting programs available in SMEs of Malaysian ICT sector are currently low compared to developed countries, though the Malaysian Government has taken initiative in this regard through $8^{\text {th }}$ Malaysia plan [12]. This research concludes and the author strongly believes that the Malaysian SMEs can deploy TC successfully provided they perform the necessary feasibility study, come up with a clear business plan, create a CCB within the organization and prepare the people in the organization with adequate trainings. 


\section{REFERENCES}

[1] Watson, I. \& Lightfoot, D. J. (2003). Mobile working with Connexions. Emerald Insights. Volume 21. Number 13/14. pp 347-352. MCB University Press Ltd. Available at www.emeraldinsight.com (Accessed: 27th Sept 2010).

[2] Franks, J. (1998). The Virtual Organisation. Emerald Insights. 47(4), 130-134. MCB University Press Ltd. Available at http://www.emeraldinsight.com (Accessed: $24^{\text {th }}$ Sept 2010).

[3] Roseberry, C. (2006). Top 10 Remote Work Myths \& Realities. Mobile Office Technology. About Inc. A part of The New York Times Company. Available at http://mobileoffice.about.com/od/getmobilized/tp/mythsrea lity.htm (Accessed: 24 ${ }^{\text {th }}$ March 2011).

[4] Subrahmanyam, K. , Sadiq, I. \& Rod, A. D. L. (2008), 'An Evaluation of Malaysian ICT Sectors Readiness for Telecommuting', IEEE XPlore, Volume 3, 26-28 Aug. 2008, pp 1- 5, ISBN: 978-1-4244-2327-9.

[5] Rapoport, R.N. (1970), “'Three dilemmas of action research", Human Relations, Vol. 23, pp. 499-513.

[6] Checkland, P. and Scholes, J. (2001) Soft systems methodology in action. Chichester: Wiley.

[7] Rose, J., (2002) Interaction, transformation and information systems development - an extended application of Soft Systems Methodology, Information Technology and People, Vol. 15, No. 3, pp. 242-268.

[8] Checkland, P. (2002) 'Systems Thinking, Systems Practice: including a 30-year retrospective' Wiley.

[9] Schwalbe, K (2009) Information Technology Project Management, 6th edition, Cengage Learning, Florence, KY.

[10] Wilson, B. (2001) 'Soft systems methodology : conceptual model building and its contribution' Chichester: Wiley.

[11] Dick, B. (2002) Soft systems methodology. Session 13 of Areol - action research and evaluation on line. URL http://www.uq.net.au/action_research/areol/areolsession13.html (Accessed: 20th February 2011).

[12] Malaysia, Economic Planning Unit, Eight Malaysia Plan 2001-2005.

Available http://www.epu.jpm.my/new\%20folder/development\%20pl an/RM8/c13_cont.pdf (Accessed: 27th February 2010).

[13] Mingers, J. (Ed.) (1993), "Soft systems methodology and information systems special issue", Systemist 14 (3), pp. 82-8.

[14] Steve Haines (n.d.), "Systems Thinking: The Essence and Foundation", Available at: http://www.hainescentre.com/ systems-thinking/analytic-vs-systems-thinking.html (Accessed: 20th April 2011). 